\title{
A SERRA E A CIDADE: O TRIÂNGULO DOURADO DO REGIONALISMO
}

\author{
Maria Beatriz Rocha-Trindade \\ Âncora Editora, 2009, 143p.
}

A autora deste livro, publicado em Portugal, Maria Beatriz RochaTrindade, é uma das maiores referências no estudo da história recente da emigração portuguesa. Com a bagagem de anos de interesse pelos imigrantes portugueses em vários países europeus, e à frente do Centro de Estudos das Migrações e das Relações Interculturais, da Universidade Aberta de Lisboa, oferece neste livro um retrato vivo da ação positiva das associações de migrantes na revitalização de suas terras de origem. Tratase de organizações coletivas animadas por migrantes originários da Serra do Açor, região central de Portugal, particularmente dos concelhos de Arganil, Góis e Pampilhosa da Serra, que se estabeleceram em Lisboa desde primórdios do século XX. Como a autora deixa claro em uma nota prévia, é um livro sobre o regionalismo e os "regionalistas", tributo e retrato da cultura do migrante expressa nessas organizações, e de sua incidência social na valorização de seu meio de origem, "desde há décadas e onde quer que se encontrem".

Mesmo tratando da ação de associações de migrantes, o livro parece ter seu foco central na "Serra" de onde saíram os migrantes, o que se percebe pelos títulos das grandes partes do livro. A primeira parte, "A Serra", procura fazer justamente um retrato ao mesmo tempo geográfico, ecológico, demográfico e afetivo dessa região, em que contam tanto as informações científicas como as impressões dos viajantes. De um lado, através de vários mapas e indicadores populacionais, existe a busca em fazer sobressair sua povoação historicamente dispersa, devido ao território montanhoso e pouco fértil, e seu isolamento em relação ao restante do país devido à ausência de estradas. A pobreza em recursos naturais, equipamentos sociais e oportunidades econômicas, além do descaso das autoridades públicas, fizeram que uma crescente onda migratória 
se dirigisse, desde o princípio do século XX, para longe da Serra, tendo como atração principal a cidade de Lisboa, além de outros países. Esse processo tem levado a um progressivo esvaziamento populacional e a um envelhecimento dos remanescentes no território. Por outro lado, em contraponto com esses dados preocupantes, vistos com um "olhar de cima" como num "satélite", está o convite a assumir a "vista do viajante", a contemplar a beleza natural, se embrenhar pelos caminhos da Serra, experimentar a dificuldade de deslocamento, ver e ouvir a memória expressa tanto pela fala de seus habitantes, como também pela visão de suas antigas construções, ou de seus edifícios novos construídos com os recursos dos emigrados. Talvez não tenha outro sentido, a não ser essa memória contemplativa, a longa listagem das freguesias pertencentes aos três concelhos estudados, como um "exercício de conhecimento da toponímia popular portuguesa".

A segunda parte, "da Serra para a cidade", faz um histórico da migração portuguesa para Lisboa, tendo como foco a população emigrada da Serra. As condições difíceis na região de origem, ao lado das ofertas de emprego na região de Lisboa, levaram à saída de vários conterrâneos, o que não tardou a gerar uma verdadeira cultura migratória que se estende por gerações. A migração para Lisboa, inicialmente individual, concentrandose em alguns empregos de baixa qualificação, através de suas redes de sociabilidade apoiadas no meio de origem, gerou verdadeiros nichos de inserção profissional no espaço urbano de Lisboa. Empresas foram criadas pelo esforço de gerações de migrantes e se tornaram paradigmas de sucesso profissional. A autora relata três casos exemplares dessa perseverança dos migrantes num mesmo ramo profissional: leitarias e pastelarias por migrantes de Arganil; táxis e transporte de mercadorias por migrantes de Cortes, freguesia de Alvares, concelho de Góis; sucateiros ou reciclagem de metais por migrantes da freguesia de Pessegueiro, concelho de Pampilhosa da Serra. Também nessa parte, a autora faz um exercício de conceituação em torno de designações como "pátria", caracterizada pela sua abstração remetendo à nação; "região", como referência ao território no seu sentido mais largo (a "Serra do Açor" neste caso) e os "lugares", as "aldeias", as "vilas", ou como dizem os migrantes, a "minha terra", como designação afetiva para com os lugares, mais visíveis, palpáveis, memoráveis, em que existe uma personalização de sua ascendência campesina. É em torno desses lugares, muitas vezes minúsculos, que se desenvolve a vitalidade do associativismo dos migrantes, polarizado entre a cidade e a Serra.

A terceira parte, "em torno do regionalismo", retrata o desenvolvimento das associações de migrantes que encontraram unanimemente sua razão 
de ser na sua identidade regional. Para tanto, a autora começa distinguindo as noções de "região", de ordem geográfica; a "regionalização", de ordem político-administrativa, cuja polêmica tentativa de implantação pelas autoridades públicas será criticada pela autora; e o "regionalismo", em cujo universo de sentido se situam as associações de migrantes. A gênese do associativismo dos migrantes originários da Serra se encontra em Lisboa, como iniciativa genuína da sociedade civil, não dependendo de governos, de referendos ou de decisões legislativas. Foi num contexto de intensa migração, ao despovoar a Serra, que as associações regionalistas foram surgindo, com seu apego às origens, criando e tornando operativos os laços de afeto e solidariedade entre os que saíram e os que ficaram. O livro relaciona várias citações de autores regionalistas conhecidos para ressaltar esses aspectos comuns do regionalismo: a importância da migração, a experiência da saudade, a força agregadora das redes de migrantes, a busca de suprir as carências daquelas localidades, a polaridade entre Serra e cidade, a vivência imaginária e real do retorno. De fato, esses traços sobressaem quando se descreve o modo de constituição e atuação dessas associações, com as prioridades que vão se alterando ao longo do tempo: desde a preservação cultural e as oportunidades de convivência até as obras visando ao desenvolvimento sustentável da região.

Na parte, "entre a Serra e a cidade", a autora descreve as atividades desenvolvidas em geral por essas associações, como parte de seu calendário anual: as reuniões plenárias, as festas comemorativas, os almoços solenes, os piqueniques, as festas religiosas na Serra. Detém-se, também, nas suas formas de cotização e financiamento, nos rituais e protocolos que regem todos os eventos, os intercâmbios entre as diferentes associações, os tempos e espaços que regulam essas atividades. Mais importantes são os meios mobilizados para efetivar os laços de solidariedade entre os migrantes e os habitantes da Serra: a persistente reivindicação de construção de meios para vencer o isolamento da região, o desenvolvimento de uma imprensa regional e local extremamente ativa, que serve também de memória escrita e iconográfica para a história local, a presença da rádio, e a realização de congressos, colóquios e encontros regionalistas para debater a história e a realidade regional. $\mathrm{O}$ espaço do associativismo é também o ambiente propício para se construir a notoriedade de várias personalidades locais, oriundas da migração ou não, que contribuíram para o desenvolvimento regional. A autora faz um levantamento de várias dessas personalidades, além de listar de forma minuciosa a rede de estruturas associativas.

A última parte do livro, "novas imagens da Serra", faz questionamentos sobre o futuro do movimento regionalista frente ao retrato persistente da 
crise: a diminuição continuada da população da Serra e seu progressivo envelhecimento, que vem tornando inviável o funcionamento mesmo de vários serviços públicos, como a saúde e a educação. Resgatando a trajetória desse movimento associativo vê que sua importância permanece, sobretudo, no relacionamento frente ao poder público, no sentido de contribuir para um planejamento estratégico visando o desenvolvimento da globalidade da região da Serra, articulando estruturas associativas e administrações regionais.

Trata-se de um livro que busca ir além da informação e análise sociológica, procurando despertar o leitor para outros universos de sentido que o possam associar à paisagem da Serra e às imagens dos grupos ligados ao movimento associativo dos migrantes. Nesse sentido, o livro é enriquecido por belíssimas fotos de Jorge Barros, que são mais do que meras ilustrações, mas o veículo para um diálogo entre o texto e a iconografia que coloca o leitor no ambiente da Serra, de seus vilarejos, mas também no seio das coletividades dos migrantes. Esse mútuo enriquecimento que restitui a humanidade dos migrantes estudados é buscado em várias alusões a outras artes, como o trocadilho do título, referindo-se à obra de Eça de Queiroz ("A cidade e as serras"), ou, então, a referência ao filme recentemente lançado, inclusive na cidade de São Paulo, "Aquele querido mês de agosto", de Miguel Gomes, que traz uma visão lírica do mês de férias dos emigrados portugueses, encontrados em suas muitas festas nessa mesma região estudada no livro. Entretanto, essa busca de atiçar outros sentidos para o tema em estudo é também mobilizada por outros recursos encontrados na obra: o levantamento dos nomes das localidades da Serra, a história de famílias de emigrantes bem sucedidos, a descrição das atividades das associações, as placas e monumentos, a citação de regionalistas conhecidos, entre outros.

Essa talvez seja a grande riqueza do livro. Na busca de tornar palpável o paradoxo entre o esvaziamento populacional de uma região praticamente estéril, sob o ponto de vista econômico, e o amor devotado pelos migrantes desenraizados, que se afastaram de sua terra em busca da ascensão social em Lisboa, a autora mostra o roteiro criado pelos próprios emigrantes para reconstruírem sua autoestima. No empenho do movimento associativo de, a partir da cidade, recuperar e renovar a Serra, é sempre do retorno que se trata. Num percurso cheio de alusões literárias e poéticas que remetem ao significado de "ser português", o sentido do termo "saudade", encontramos o paradoxo da cultura migratória portuguesa, enunciado pela própria autora:

Existe na mentalidade tradicional dos portugueses uma faceta 
marcadamente contraditória, no que toca à sua ligação afetiva com a terra de nascimento. Aparentemente, desligam-se dela com alguma facilidade, não hesitando a deixá-la (...) E, no entanto, quando partem, já levam a intenção e a motivação, para regressar, para reatar os laços criados desde o nascimento, por muito longa que possa ser a separação e muito profundo o corte com o país de origem (p. 47).

É o paradoxo de uma emigração que ao mesmo tempo esvazia o território, cria a dinâmica cultural que suscita o despertar para a sua beleza e valorização social e política. No exercício do diálogo e trânsito entre a sociologia, a literatura e a poesia, a fotografia e a imagética, passando pelos caminhos da geografia, entramos no campo da "evocação". É a concretude adquirida por esse universo de sentido, a incidência social e política dessa relação intersubjetiva, que descobrimos ao apreciar esse livro. Ele pode nos ajudar a descobrir outros tantos universos evocativos, e socialmente palpáveis, que os migrantes também estão criando entre nós.

Sidnei Marco Dornelas Assessor Setor Pastoral da Mobilidade Humana - CNBB 